Eine ähnliche Anlage befindet sich in Bordeaux; in Marseille stehen 3 Kammern von 10,20 und $50 \mathrm{~m}^{3}$, je eine Anlage ist in Martinique und Tunis, 3 in Marokko, 6 in Algerien ( 2 in Algier, je 1 in Bongie, Biskra, Oran und Philippeville). In Le Havre hat man schon frische amerikanische Äpfel zur Vermeidung der Einschleppung der San-José-Schildlaus behandelt. In Algerien arbeitet man nur gegen Tabakkäfer an Tabak und Ephestia-Arten an Datteln und Feigen.

Jede Kammer besitzt einen Generator, eine Entlüftungseinrichtung, einen Manometer und Registrierapparate für die Temperatur und Gaskonzentration. Als Bekämpfungsmittel kommt neben $\mathrm{CS}_{2}$ auch Blausäure in Form des Bottichverfahrens mit nachfolgender Neutralisation in Frage. Es wird laufend für die Begasung von Äpfeln, Orangen, Zitronen, Trauben und Tomaten angewendet und hat den Vorteil, daß nicht die geringsten Spuren des Gases zurückgehalten werden. Bei Birnen und Bananen muß vorsichtig dosiert werden, weil sie sich sonst schwarz färben.

Ferner wird Brommethyl und Äthylenotyd angewendet. Interessant ist die hier zum erstenmal in der Literatur vertretene Auffassung, daß ein besonderer Vorteil des Äthylenoxyds darin zu. sehen ist, daB es sich innerhalb einer gewissen Zeit zu dem gänzlich ungefährlichen Glykol umbildet. Hindernis für seine allgemeine Anwendung ist nur der hohe Preis und die Tatsache, daß Gemüse und frische Früchte in ihrer Beschaffenheit beeinträchtigt werden, wenn man nicht sehr viel Kohlensäure gleichzeitig verwendet.

Tetrachlorkohlenstoff, Äthylendichlorid, rein oder in Mischung mit ersterem, Äthylacetat, Äthyl- und Methylformiat müssen wegen unsicherer Wirkung, ChIorpikrin und andere wegen Beeinträchtigung des Geruches oder Geschmackes von der Schädlingsbekämpfung ausgeschlossen werden.

Die guten Erfolge des Verfahrens haben zur Planung weiterer Anlagen in Frankreich und seinen Koionien geführt.

Raseh.

Roark, R. C., Organische Schädlingsbekämpfungsmittel. (Insecticides and fungicides.) Ind. and Eng. Chem. 1935 (27) 5, 530,32.

$\mathrm{Da}$ anorganische Schädlingsbekämpfungsmittel oft auf Früchten usw. einen die menschliche Gesundheit schädigenden Rückstand hinterlassen, gehört die $\mathrm{Zu}$ kunft den organischen Stoffen, die für die Insekten giftiger und für die Wirbeitiere weniger giftig sind. Derartige Stoffe können Pflanzenauszäge sein oder synthetisch aus Derivaten von Naturgas, Petroleum, Kohle usw. hergestellt werden. Sie brauchen nicht wie Nikotin, Rotenon und Pyrethrin kompliziert aufgebaut zu sein, denn auch relativ einfach aufgebaute Verbindungen besitzen hohe insektentötende Kraft. Die Prüfung der letzteren muß unbedingt durch eine pharmakologische Prüfung ergänzt werden, um Schäden an Menschen und Haustieren zu vermeiden. Unter den erläuterten Beispielen befinden sich auch die Thiocyanate.

Rasch.
Holzbeschädigung durch den ,Meerwarm". ")

In der letzten Zeit beklagen sich die Forstbetriebe im russischen Fèrneñ 0 sten über den hohen Schaden, welcher dem im Meereswasser (Stiller Ozean) Iagernden Rundholz durch den sogenannten "Meerwurm" (ein Wurm aus der Gattung der Feretinidae) zugefügt wird, der seine Gänge in Balken bohrt; diese Gänge mit eingr Eingangsöffnung von unter $1 \mathrm{~mm}$ im $\Phi$ erweitern sich dem Balkeninnern zu und machen allmählich das Holz gänzlich unbrauchbar. Das vom Meerwurm befallene Holz verbreitet einen besonderen Geruch, an dem man den Schaden schon von weitem erkennen kann. Die Gänge gehen allerdings nie über die Wasserlinie hinaus. Der Schaden ist weit böher bei geschälten Balken als bei ungeschälten. Zur Bekämpfung des Übels wird empfohlen, die Zeit der Holzlagerung im Meereswasser möglichst einzuschränken, besonders aber die vom Meerwurm bereits befallenen Balken sofort aus dem Wasser zu ziehen und sie im Trockenen aufzustapeln. Verbältnismäßig gering ist die Gefahr in der Nähe der Flußmündungen, wo das Wasser einen niedrigeren Salzgehalt aufweist. Jemtzeff-Berlin.

1) ,Forstwirtsch. u. Expl." 11, 1935. Lenjugr. *

\section{Spechthieb an einer abgestorbenen Kiefer} in Grunewald.

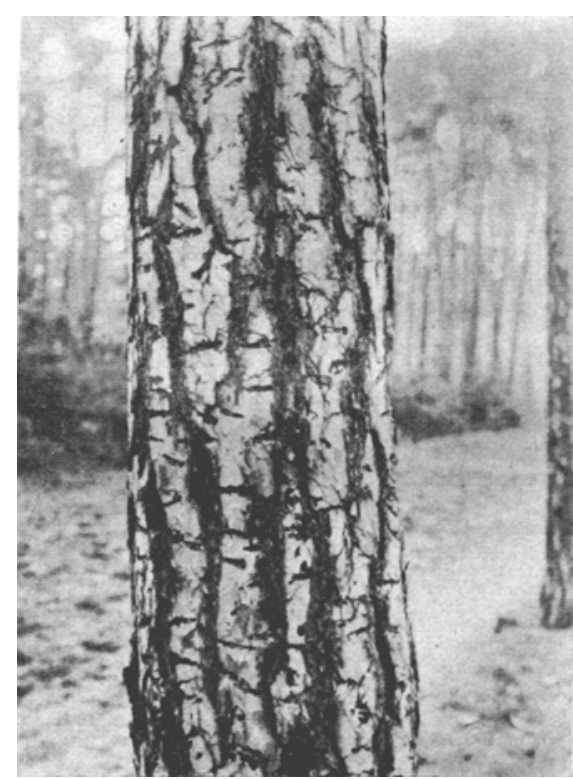

Kiefer vom Schwarzspecht bearbeitet.

Phot. Fr. Berndt, Berlin-Reinickendorf.

Gelegentlich eines forstentomologischen Ausflugs des Deutschen Naturkundevereins e. V., Zweigverein Berlin, in den Grunewald, konnte ich eine Kiefer zejgen, deren Wipfel trocken, deren borkige Rinde vom Schwarzspecht bearbeitet war. Die Abb. zeigt die sehr charalteristischen, horizontal geführten Schnabelhiebe. Eckstein. 